\title{
Vaginal noise: prevalence, bother and risk factors in a general female population aged $45-85$ years
}

\author{
Marijke C. Ph. Slieker-ten Hove • Annelies L. Pool-Goudzwaard • \\ Marinus J. C. Eijkemans • Regine P. M. Steegers-Theunissen • Curt W. Burger • \\ Mark E. Vierhout
}

Received: 8 November 2008 / Accepted: 20 March 2009/Published online: 18 April 2009

(C) The Author(s) 2009. This article is published with open access at Springerlink.com

\begin{abstract}
Introduction and hypothesis Vaginal noise (VN) is a symptom of pelvic floor (PF) dysfunction and has been described in a few studies. No other risk factors have been described besides parity and pelvic organ prolapse (POP). Underlying mechanisms of $\mathrm{VN}$ are unclear. Aims of this study were to describe prevalence, bother and relation between VN and PF (muscle)(dys)function.

Methods A cross-sectional study was performed on a general population of 2,921 women (aged 45-85 years). Questionnaires were filled in by 1,397 women, and 800 were selected at random to undergo vaginal examination for
\end{abstract}

M. C. Ph. Slieker-ten Hove • R. P. M. Steegers-Theunissen •

C. W. Burger

Department of Obstetrics and Gynaecology,

Erasmus MC, University Medical Centre,

Rotterdam, The Netherlands

M. C. Ph. Slieker-ten Hove

Cobra Research Institute,

Amersfoort, The Netherlands

\author{
A. L. Pool-Goudzwaard \\ Department of Neuroscience, Erasmus MC, \\ University Medical Centre, \\ Rotterdam, The Netherlands
}

\section{J. C. Eijkemans}

Department of Public Health, Erasmus MC,

University Medical Centre,

Rotterdam, The Netherlands

R. P. M. Steegers-Theunissen

Department of Epidemiology,

Erasmus University Medical Centre,

Rotterdam, The Netherlands
POP Quantification and PF muscle function assessment. Chi-square tests, Student's $t$ test and multivariate logistic regression were performed $(P<0.05)$.

Results Response rate was $62.7 \%$. Prevalence of VN was $12.8 \% ; 72.1 \%$ reported only a little bother. Odds ratios for parity and solid stool were high.

Conclusions VN was strongly related to many symptoms of pelvic floor dysfunction, but it was only causing a little bother.

Keywords Pelvic floor dysfunction .

Pelvic floor musculature $\cdot$ Risk factors $\cdot$ Vaginal noise

\section{R. P. M. Steegers-Theunissen}

Department Paediatrics/Paediatric Cardiology, Erasmus MC, University Medical Centre,

Rotterdam, The Netherlands

R. P. M. Steegers-Theunissen

Department of Clinical Genetics, Erasmus MC,

University Medical Centre,

Rotterdam, The Netherlands

C. W. Burger

Division of Gynaecology and Gynaecologic Oncology,

Erasmus MC,

University Medical Centre,

Rotterdam, The Netherlands

\section{E. Vierhout}

Department of Obstetrics and Gynaecology,

Radboud University Nijmegen Medical Centre,

Nijmegen, The Netherlands

M. C. Ph. Slieker-ten Hove ( $\square)$

Softwareweg 5,

3821 BN Amersfoort,

The Netherlands

e-mail: m.slieker@somt.nl 


\section{Introduction}

Many older women have symptoms of pelvic floor dysfunction that can be a cause of social distress and loss of quality of life due to taboo and shame about these conditions [1-5]. Frequently described symptoms of pelvic floor dysfunction include vaginal bulging, micturition problems (e.g. urinary incontinence (UI) and dysfunctional voiding), defaecation symptoms (e.g. faecal incontinence and obstruction) as well as vaginal and sexual dysfunction (e.g. dyspareunia [1, 3-8]). In our experience, it is not uncommon for women to experience vaginal noise (VN), especially during posture changes and sexual intercourse. $\mathrm{VN}$ is typically described as a very weak sound, very similar to, but far weaker than, anal flatus.

Recently, the symptom of VN has been described in a group of six women who visited a tertiary care pelvic floor referral centre [9]. No prevalence data were given. The results showed that $\mathrm{VN}$ was not associated with pelvic floor muscle (PFM) dysfunction because PFM training was ineffective for VN. A few studies have emphasized that PFM contraction in response to vaginal or rectal distension may cause VN. However, this does not explain the mechanism of air being sucked into the vagina [10-12]. The underlying mechanism of $\mathrm{VN}$ is still unknown. It is possible that air becomes trapped in the posterior fornix and that during sudden movements it is released and produces the typical noise [13].

Aims of the present study were (1) to determine the prevalence of $\mathrm{VN},(2)$ to measure the amount of bother caused by this symptom, (3) to search for possible risk factors, such as symptoms of PFM (dys)function (muscle strength, endurance, urethral lift and reflex contraction), (4) to document the severity of pelvic organ prolapse (POP; stages $0-4$ according to the pelvic organ prolapse quantification (POPQ) and the nine-point notation of the POPQ) and (5) to explore sexual activity (yes/no) and symptoms of PF in a general population of women aged $45-85$ years.

\section{Materials and methods}

This study is part of a large cross-sectional study that was performed on a general population of mostly white Dutch women aged 45 to 85 years. Figure 1 presents the flowchart of the study.

The total population of women aged $45-85$ years $(n=$ 2,921 out of 16,000 citizens), registered on the patient lists of eight out of the nine general practitioners in the town of Brielle (near Rotterdam, the Netherlands), were approached to participate in the present study. Names and addresses were obtained from the general practitioners. As all the inhabitants are obliged to register with a general practitioner, the study population included $95 \%$ of all the women in this age range. The women were sent information about the study and could enrol by filling out an informed consent form. They were offered three options: to sign a refusal form, to fill out the questionnaire only or to fill out the questionnaire and undergo vaginal examination.

All the women were asked to complete a self-report questionnaire. Non-responders received a reminder 8 weeks later that contained the same questionnaire. Data were collected anonymously. To avoid selection bias, nonresponders were invited to complete a short questionnaire that comprised five questions about: age, parity, presence of urinary stress incontinence (yes/no), faecal incontinence (yes/no) and feeling vaginal bulging (yes/no). To encourage a high response to the questionnaire, we used envelopes with the name and logo of the Erasmus University, coloured paper and stamped-addressed return envelopes [14]. Each reminder included the same questionnaire.

\section{Self-report postal questionnaire}

The questionnaires used in this study combined several validated Dutch versions of pelvic floor questionnaires, such as the Urogenital Distress Inventory [15] and the Defaecation Distress Inventory [16]. In addition, subjects were asked about ethnicity, parity, vaginal bulging, incontinence, family history, menopausal state, hormone replacement therapy, previous pelvic floor surgery, educational level, smoking and heavy physical work currently or in the past. One question on $\mathrm{VN}$ was included in the questionnaire: 'Do you ever experience $\mathrm{VN}$, for example when changing from a sitting to a standing position or vice versa?' If the answer was yes, the further enquiry 'How much are you bothered by this?' could be answered on a 4-point Likert scale: 'not at all', 'a little', 'moderately', 'very much'.

Vaginal examination

From all the participants who gave informed consent to undergo vaginal examination $(n=1,140), 800$ women were randomly selected for POPQ measurement and PFM function testing (All the response forms were coded with a number that identified the woman's age, and then a research assistant selected the study sample at random). The POPQ was introduced by the International Continence Society (ICS). It has become widely accepted and has proven to be valid [17] and reliable [18]. PFM was tested for strength (absent, weak, normal, strong), endurance (0-10 s), the ability to achieve urethral lift (yes/no) and an effective reflex contraction during coughing (that resulted in inward perineal movement, yes/no).

One gynaecologist and one physiotherapist performed the vaginal examinations. They practiced the vaginal 
Fig. 1 Flowchart of the study

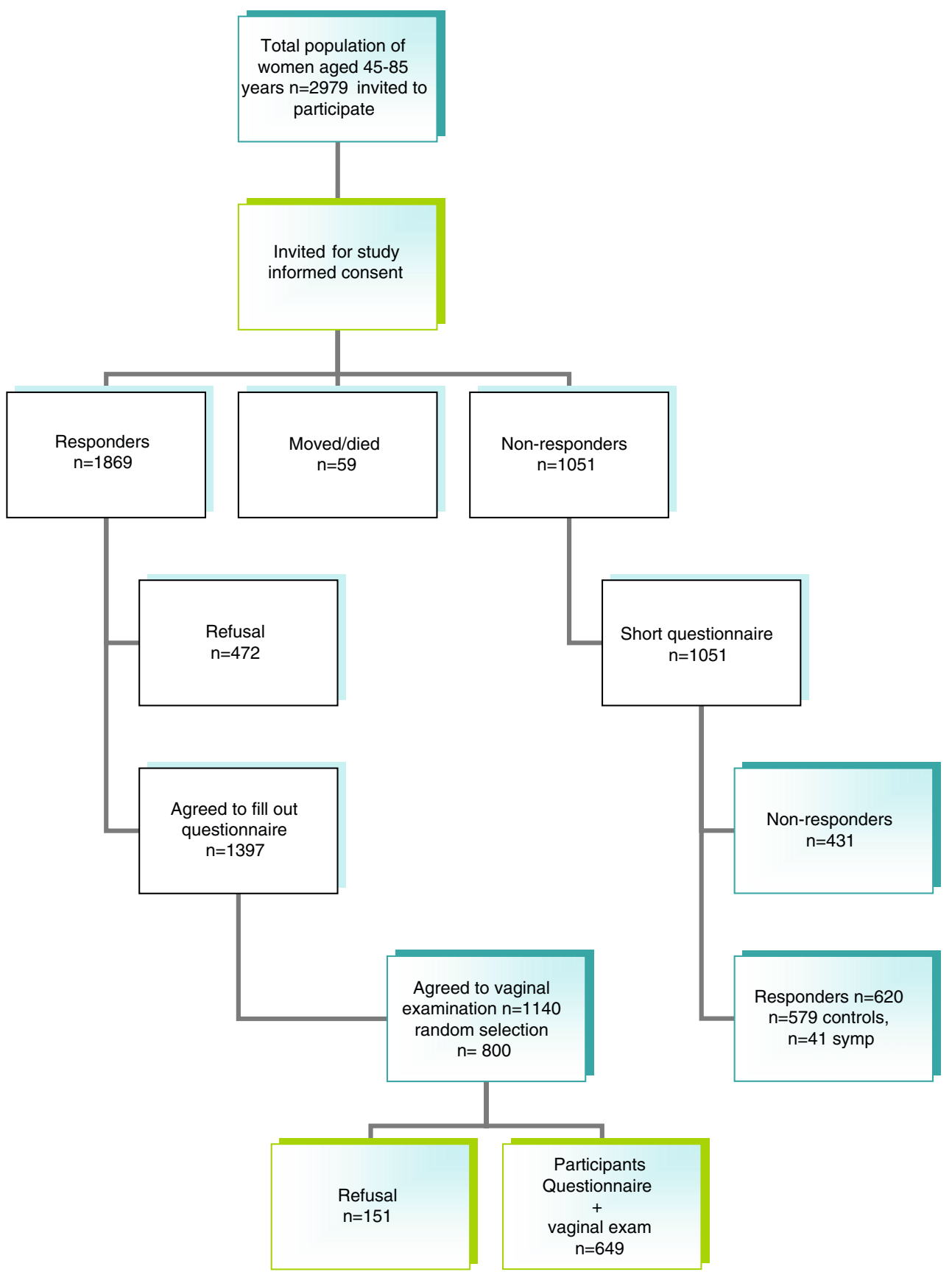

examination protocol until they reached agreement about the test and registration scores. This process was performed at the Pelvic Floor Centre of the Erasmus Medical Centre in Rotterdam. POPQ measurements were carried out in conformity with the ICS standardisation report [17]. After each vaginal examination, all the details were entered into the three-by-three POPQ grid. Four PFM items were tested according to the new terminology $[19,20]$. The two examiners were blinded to the results of the questionnaire. All the vaginal examinations were performed in the second half of the day, between 1400 and 2100 hours. The women were asked to empty their bladder before the examination.
Participants were assigned to one of the five ordinal stages of prolapse $(0-4)$ in accordance with the POPQ grading system. All the methods, definitions and descriptions were in line with the ICS [17].

\section{Statistical analysis}

The analyses were performed using the Statistical Package for the Social Sciences (SPSS) 15.0. To determine differences between the women with complaints of $\mathrm{VN}$ and those women without, chi-square tests were used on categorical items and Student's $t$ test on continuous items. To determine 
potential risk factors for $\mathrm{VN}$, multivariate logistic regression was used with backward stepwise elimination of variables at the level $P<0.05$. Results were obtained as odds ratios (ORs) with $95 \%$ confidence intervals. Associations between the nine-point notation of the POPQ and VN were tested using multivariate logistic regression. The Medical Ethics Research Committee of the Erasmus Medical Centre in Rotterdam, the Netherlands, approved this study.

\section{Results}

The response rate to the questionnaire was $62.7 \%(1,869 /$ $2,979)$. In the group of 1,869 responders, 472 women refused to participate, 1,397 agreed to fill out the large questionnaire, and 1,140 agreed to fill out the questionnaire and undergo vaginal examination. In the non-responder group, 59\% filled out and returned the short questionnaire (620/1,051). There were no significant differences between the non-responders group and the responders group between the five asked items. Vaginal bulging was reported by $6.7 \% \quad(n=41)$ compared to $9.8 \%$ in the group of participants $(135 / 1,397)$. In the group who consented to undergo vaginal examination $(n=1,140), 800$ women were selected at random and sent an invitation; 649 women complied $(81.1 \%)$.

Table 1 presents the baseline characteristics. There were positive responses to the question on $\mathrm{VN}$ in $12.8 \%$ of the women $(176 / 1,378 ; 19$ responses on $\mathrm{VN}$ were missing). The vast majority $(96 \%)(n=169 / 176)$ were not at all

Table 1 Baseline characteristics of the total study population, those who underwent a physical examination and the non-responder group, expressed as numbers (\%) and means

\begin{tabular}{|c|c|c|c|}
\hline Characteristics of the total study population & Questionnaire total & Physical exam total & Study group vaginal noise \\
\hline & $n=1,397$ & $n=649$ & $n=175(12.8)$ \\
\hline Mean age (range $45-84$ years) & $58.0(\mathrm{SD} \pm 9,2)$ & 58.3 & $56.5(\mathrm{SD} 8.11)$ \\
\hline \multirow[t]{2}{*}{ Mean body mass index (BMI) } & $n=1,364$ & $n=634$ & $n=173$ \\
\hline & $25,6(\mathrm{SD} \pm 3.9)$ & $25.6(\mathrm{SD} \pm 3.7)$ & $25.8(\mathrm{SD} \pm 3.8)$ \\
\hline Race & $n=1,372$ & $n=640$ & $n=174$ \\
\hline White & $1,351(96.7)$ & $632(97.4)$ & $169(97.1)$ \\
\hline \multirow[t]{2}{*}{ Non-white } & $20(1.4)$ & $8(1.2)$ & $5(2.9)$ \\
\hline & $n=1,340$ & $n=639$ & $n=176$ \\
\hline Median parity & 2 & 2 & 2 \\
\hline 0 & $120(8.6)$ & $49(7.6)$ & $6(3.4)$ \\
\hline 1 & $215(15.4)$ & $86(13.3)$ & $21(11.9)$ \\
\hline 2 & $675(48.3)$ & $321(49.5)$ & $93(52.8)$ \\
\hline$\geq 3$ & 387 (27.7) & $183(28.2)$ & $56(31.8)$ \\
\hline Menopausal status & $n=1,383$ & $n=645$ & $n=174$ \\
\hline (Pre)menopausal & $374(26.8)$ & $167(25.7)$ & $56(32.2)$ \\
\hline Postmenopausal & $1,009(72.2)$ & $478(73.7)$ & $118(67.8)$ \\
\hline Surgical history & $n=1,384$ & $n=645$ & $n=173$ \\
\hline \multirow[t]{2}{*}{ Prolapse } & $103(7.4)$ & $54(8.3)$ & $17(9.8)$ \\
\hline & $n=1,382$ & $n=643$ & $n=171$ \\
\hline \multirow[t]{2}{*}{ Incontinence } & $47(3.4)$ & $24(3.7)$ & $11(6.4)$ \\
\hline & $n=1,383$ & $n=643$ & $n=174$ \\
\hline Hysterectomy & $234(16.8)$ & $109(16.8)$ & $32(18.4)$ \\
\hline Family history & $n=985$ & $n=441$ & $n=132$ \\
\hline \multirow[t]{2}{*}{ Mother POP } & $359(25.7)$ & $161(36.5)$ & $55(41.7)$ \\
\hline & $n=870$ & $n=398$ & $n=117$ \\
\hline Mother UI & $258(29.7)$ & $122(30.6)$ & $54(46.2)$ \\
\hline Heavy physical work & $n=1,381$ & $n=642$ & $n=174$ \\
\hline \multirow[t]{2}{*}{ Current } & $269(19.3)$ & $130(20)$ & $30(17.2)$ \\
\hline & $n=1,384$ & $n=645$ & $n=175$ \\
\hline Ever & $619(44.3)$ & $293(45.1)$ & $82(46.9)$ \\
\hline
\end{tabular}


Table 2 Number of women with complaints of vaginal noise and the level of bother

\begin{tabular}{ll}
\hline Bother unknown & $1^{\mathrm{a}}$ \\
Not at all & 42 \\
A little & 127 \\
Moderate & 5 \\
Very much & 1 \\
Total & $175(12.8 \%)$ \\
\hline
\end{tabular}

${ }^{\mathrm{a}}$ One evaluation is missing

by it or only a little. In 43 women, the amount of bother was unknown (see Table 2). There were no significant differences in $\mathrm{VN}$ between the sexually active women (13.3\%) and the sexually inactive women (12.2\%). Table 3 shows the (non-significant) relation between the presence of $\mathrm{VN}$ and the POPQ stage in the women who underwent vaginal examination ( $n=635, n=14$ evaluations were missing). Analysis of the detailed nine-point notation in the POPQ grid showed that only the lowest point of the posterior vaginal wall (point $\mathrm{Bp}$ ) was significantly related to $\mathrm{VN}(P=0.003)$. Furthermore, no significant differences were found in the strength and endurance of the pelvic floor musculature, the ability to achieve urethral lift and an effective reflex contraction during coughing that resulted in inward movement of the perineum between the VN-positive and the VN-negative women.

Table 4 shows the prevalence of the risk factors in relation to vaginal noise, used for the further analysis. Table 5 shows the results of the univariate and multivariate analyses, carried out to identify risk factors for symptoms of pelvic floor dysfunction associated with VN. The univariate analysis revealed significant risk estimates, especially on parity, urinary urge and stress incontinence,

Table 3 Relation between POPQ stage and the presence of the symptom of vaginal noise in the subgroup who underwent vaginal examination (chi-square for trent $P=0.055$ ) 14 missing (six POPQ incomplete, eight $\mathrm{VN}$ question not answered)

\begin{tabular}{llr}
\hline & Vaginal noise, $n(\%)$ & Total $n$ \\
\hline Stage 0 & $18(11.4)$ & 158 \\
Stage 1 & $26(11.2)$ & 233 \\
Stage 2 & $33(15.7)$ & 210 \\
Stage 3 & $8(25.8)$ & 31 \\
Stage 4 & 0 & 3 \\
Total & $85(13.4)$ & $635^{\mathrm{a}}$ \\
\hline
\end{tabular}

${ }^{\text {a }}$ Due to missing data, percentages do not always correspond with the total group.
Table 4 Prevalence of the risk factors in relation to vaginal noise of the total study group

\begin{tabular}{lll}
\hline & Vaginal noise & \\
\hline & No & Yes \\
Urge urinary incontinence & $n=1,177$ & $n=171$ \\
& $321(27.3)$ & $74(43.3)$ \\
Stress urinary incontinence & $n=1,176$ & $n=173$ \\
Vaginal bulging & $609(51.8)$ & $119(68.8)$ \\
& $n=1,193$ & $n=172$ \\
Digital defecation & $123(10.3)$ & $36(20.9)$ \\
Liquid stool loss & $n=1,195$ & $n=174$ \\
Solid stool loss & $89(7.4)$ & $24(13.8)$ \\
& $n=1,194$ & $n=173$ \\
& $128(10.7)$ & $38(22)$ \\
& $n=1,196$ & $n=174$ \\
& $31(2.6)$ & $16(9.2)$ \\
\hline
\end{tabular}

Due to missing data, percentages do not always correspond with the whole group

vaginal bulging, manual evacuation of faeces, flatal incontinence, solid stool and fluid stool incontinence, with the highest risk estimate on solid stool incontinence (OR $3.81,95 \%$ CI 2.04-7.12). In the multivariate analysis, most of the variables remained significant, with surprisingly high risk estimates on parity and solid stool incontinence of 4.51 (95\% CI 1.69-12.09) and 4.55 (95\% CI 2.22-9.32), respectively.

\section{Discussion}

VN is a well-known symptom to most gynaecologists and pelvic floor physiotherapists, but little is known about the prevalence and possible risk factors. Data from this study revealed that this symptom is not uncommon. Roughly one out of the eight women in a general population had the symptom of VN (12.8\%). This is in contrast with the data presented by Krissi et al., who did not find any cases of VN in 250 women who visited a urogynaecology clinic (2003). In a recently published article, Krissi et al. [9] claimed to be the first authors to describe "vaginal wind". However, Attapattu was the first to describe the symptom of $\mathrm{VN}$ in 1995, for which he coined the phrase 'garrulitas vulvae' (chattering vulva) [21]. In our opinion, $\mathrm{VN}$ is a better term than vaginal wind because the exact mechanism is unclear and "noise" does not connote to anal flatus.

The bother caused by VN was modest. Only six out of the $175(3.4 \%)$ women reported being moderately or very bothered by it. This seems to disagree with Krissi et al. [9], who suggested that $\mathrm{VN}$ is an extremely embarrassing 
Table 5 Results of the univariate and multivariate logistic regression $(P<0.05)$

${ }^{\text {a }}$ No association could be calculated

\begin{tabular}{|c|c|c|c|c|c|c|}
\hline & \multicolumn{3}{|c|}{ Univariate analysis } & \multicolumn{3}{|c|}{ Multivariate analysis } \\
\hline & OR & $95 \%$ & $\mathrm{CI}$ & OR & $95 \%$ & $\mathrm{CI}$ \\
\hline Age & 0.98 & 0.96 & 0.99 & 0.97 & 0.94 & 0.99 \\
\hline Parity & 2.79 & 1.21 & 6.45 & 4.51 & 1.69 & 12.09 \\
\hline BMI & 1.02 & 0.98 & 1.06 & $-^{\mathrm{a}}$ & $-{ }^{\mathrm{a}}$ & $-^{\mathrm{a}}$ \\
\hline Menopause & 0.75 & 0.54 & 1.06 & $-^{\mathrm{a}}$ & $-{ }^{\mathrm{a}}$ & $-^{\mathrm{a}}$ \\
\hline Urge urinary incontinence & 2.03 & 1.47 & 2.83 & $-^{\mathrm{a}}$ & $-{ }^{\mathrm{a}}$ & $-^{\mathrm{a}}$ \\
\hline Stress urinary incontinence & 2.05 & 1.46 & 2.99 & 1.63 & 1.11 & 2.37 \\
\hline Vaginal bulging & 2.30 & 1.53 & 3.48 & 2.36 & 1.50 & 3.72 \\
\hline Digital defaecation & 1.99 & 1.23 & 3.22 & 1.87 & 1.08 & 3.25 \\
\hline Incontinence of liquid faeces & 2.34 & 1.57 & 3.51 & 2.07 & 1.31 & 3.26 \\
\hline Incontinence of solid faeces & 3.81 & 2.04 & 7.12 & 4.55 & 2.22 & 9.32 \\
\hline Incontinence of flatus & 2.92 & 2.07 & 4.13 & 2.34 & 1.59 & 3.42 \\
\hline
\end{tabular}

problem, although they did not test for the bother of VN. The low bother score reported by the vast majority of women might partly explain the lack of attention that the symptom has received in the literature.

We were unable to find an association with sexual activity, which suggests that the symptom of VN does not influence sexual activity. In our analysis to explore the relation to the POPQ score, the prevalence of $\mathrm{VN}$ in POP stages 3 and 4 was twice as high as in the lower stages, although this did not reach significance possibly due to the small numbers with the higher stages. This is in line with the findings in the case report published by Krissi et al. [9].

As pelvic floor physiotherapy was not effective in the study by Krissi et al., we also tested the association between PFM function and VN. No significant differences could be demonstrated between the symptomatic and asymptomatic women, which might explain the disappointing results of PFM training in women with VN.

\section{Risk factors}

Many symptoms of pelvic floor dysfunction proved to be significant risk factors for $\mathrm{VN}$ : flatal incontinence, fluid stool and solid stool (anal incontinence) had high risk estimates. In the multivariate analysis, solid stool incontinence had the highest risk estimates (OR 4.55, 95\% CI 2.22-9.32). However, the confidence interval was wide, which influenced the strength of the OR. It is well known that anal incontinence is extremely embarrassing and has a strongly negative influence on quality of life $[22,23]$. This might also explain the low bother of $\mathrm{VN}$ if the women were comparing it to anal incontinence. It is difficult to formulate an explanation for $\mathrm{VN}$ associated with solid stool incontinence, but we assume that diminished function of the internal anal sphincter (responsible for passive closure of the rectum) can play a role because PFMF was not associated with VN. Parity has also been hypothesized to be the major risk factor [9]. Our univariate and multivariate analyses reinforced the importance of the risk factor parity (OR 4.51).

\section{Underlying mechanism of $\mathrm{VN}$}

In 1996, Nokes et al. reported the existence of intravaginal air in $11 \%$ of their (normal) radiology patients, but nothing was mentioned about the escape of vaginal air [24]. Analysis of the first notation of the POPQ in the nine-point grid revealed that the $\mathrm{Bp}$ point was of significant importance, which might reflect anatomical changes that partly explain the development of $\mathrm{VN}$. We hypothesize that a significantly high score on the posterior vaginal wall (point Bp) means that the vagina remains closed during changes of position from sitting to standing or vice versa.

\section{Limitations}

This study had some limitations. The questionnaire was long, and not all women can be expected to want to undergo the burden of vaginal examination. Therefore, selection bias may have occurred. The women may have opted to participate due to their symptoms, which would have overestimated the prevalence and bother of $\mathrm{VN}$.

In conclusion, $\mathrm{VN}$ was not uncommon in our studied Dutch women aged 45-85 years. It was strongly related to many symptoms of pelvic floor dysfunction, with the highest risk estimates on parity and solid stool incontinence. Although VN was found to have a low bother score, it can be very embarrassing to some women and therefore deserves more attention than it has received until now. Based on the results of our study, it is unclear which therapy is most suitable for this symptom. 
Acknowledgement We thank Mrs. G.M. Schoenmaker, MD, from the General Practitioner Group Brielle, The Netherlands, for her assistance and cooperation.

Conflicts of interest None.

Funding Unrestricted grant from NV Organon, Oss, The Netherlands.

Open Access This article is distributed under the terms of the Creative Commons Attribution Noncommercial License which permits any noncommercial use, distribution, and reproduction in any medium, provided the original author(s) and source are credited.

\section{References}

1. Eva UF, Gun W, Preben K (2003) Prevalence of urinary and fecal incontinence and symptoms of genital prolapse in women. Acta Obstet Gynecol Scand 82:280-286

2. Uustal Fornell E, Wingren G, Kjolhede P (2004) Factors associated with pelvic floor dysfunction with emphasis on urinary and fecal incontinence and genital prolapse: an epidemiological study. Acta Obstet Gynecol Scand 83:383-389

3. Maclennan AH, Taylor AW, Wilson DH, Wilson D (2000) The prevalence of pelvic floor disorders and their relationship to gender, age, parity and mode of delivery. Bjog 107:1460-1470

4. Swift S, Woodman P, O'Boyle A, Kahn M, Valley M, Bland D et al (2005) Pelvic Organ Support Study (POSST): the distribution, clinical definition, and epidemiologic condition of pelvic organ support defects. Am J Obstet Gynecol 192:795-806

5. Nygaard I, Bradley C, Brandt D (2004) Pelvic organ prolapse in older women: prevalence and risk factors. Obstet Gynecol 104:489-497

6. Swift SE, Pound T, Dias JK (2001) Case-control study of etiologic factors in the development of severe pelvic organ prolapse. Int Urogynecol J Pelvic Floor Dysfunct 12:187-192

7. Kahn MA, Stanton SL (1997) Posterior colporrhaphy: its effects on bowel and sexual function. Br J Obstet Gynaecol 104(1):82-86

8. Nichols CM, Ramakrishnan V, Gill EJ, Hurt WG (2005) Anal incontinence in women with and those without pelvic floor disorders. Obstet Gynecol 106(6):1266-1271

9. Krissi H, Medina C, Stanton SL (2003) Vaginal wind-a new pelvic symptom. Int Urogynaecol J 14:399-402

10. Filipini DL, Dubrovsky B (1991) Pelvic floor muscles response to graded rectal distension and cutaneous stimulation. Dig Dis Sci 36:1761-1767
11. Shafik A (1993) The recto-levator reflex: the distension of a new reflex and its clinical application. Preliminary report. Clin Physiol Biochem 10:13-17

12. Shafik A (1995) Vagino-levator reflex: description of a reflex and its role in sexual performance. Eur J Obstet Gynecol Reprod Biol 60:161-164

13. Hadar H, Kornreich L, Heifettz M, Herskovitz P, Horev G (1991) Air in vagina. Indicator of intrapelvic pathology on CT. Acta Radiol 32:170-173

14. Edwards P, Roberts I, Clarke M, Diguiseppi C, Pratap S, Wentz R et al (2002) Increasing response rates to postal questionnaires: systematic review. BMI 324:1183

15. Van Der Vaart CH, De Leeuw JR, Roovers JP, Heintz AP (2000) [The influence of urinary incontinence on quality of life of community-dwelling, 45-70 year old Dutch women] De invloed van urine-incontinentie op de kwaliteit van leven bij thuiswonende Nederlandse vrouwen van 45-70 jaar. Ned Tijdschr Geneeskunde 144:894-897

16. Van Brummen HI, Bruinse HW, Van De Pol G, Heintz AP, Van Der Vaart CH (2006) Defecatory symptoms during and after the first pregnancy: prevalences and associated factors. Int Urogynecol J Pelvic Floor Dysfunct 17:224-230

17. Bump RC, Mattiasson A, Bo K, Brubaker LP, Delancey JO, Klarskov P et al (1996) The standardization of terminology of female pelvic organ prolapse and pelvic floor dysfunction. Am J Obstet Gynecol 175:10-17

18. Swift SE (2002) Current opinion on the classification and definition of genital tract prolapse. Curr Opin Obstet Gynecol 14 (5):503-507

19. Messelink EJ, Benson T, Berghmans BJM et al (2005) Standardization of terminology of pelvic floor muscle function and dysfunction: report from the pelvic floor clinical assessment group of the International Continence Society. Neurourol Urodyn 24:374-380

20. Slieker-ten Hove MC, Pool-Goudzwaard AL, Eijkemans MJ, Steegers-Theunissen RP, Burger CW, Vierhout ME (2008) Face validity and reliability of the first digital assessment scheme of pelvic floor muscle function conform the new standardized terminology of the International Continence Society. Neurourol Urodyn

21. Attapatu JA (1995) Garrulitas Vulvae, a report of six cases. J Reprod Med 40:235-236

22. Hannaway CD, Hull TL (2008) Fecal incontinence. Obstet Gynecol Clin North Am 35(2):249-69 viii

23. Rothbarth J, Bemelman WA, Meijerink WJ, Stiggelbout AM, Zwinderman AH, Buyze-Westerweel EM et al (2001) What is the impact of fecal incontinence on quality of life. Dis Colon Rectum 44(1):76-71

24. Nokes SR, Martinez CR, Arrington JA, Dauito R (1986) Significance of vaginal air on computed tomography. J Comput Assist Tomogr 10:997-999 